\title{
OVERVIEW OF MATERIAL ANALYSIS FOR AUTOMATIC SOLAR TRACKING SYSTEM MOUNTING STRUCTURE
}

\author{
Shriram Kumaar Pandian. P, Subash.R \\ Assistant Professor, Department Of Mechanical Engineering, Tagore Engineering College, \\ Chennai, India \\ Sanjeev.D \\ Energy Asset Manager, Uvk Susnomics Engg Pvt Ltd \\ Saravana Kumar.S \\ Assistant Professor, Department Of Automobile Engineering, Eswari Engineering College, \\ Chennai, India
}

\begin{abstract}
This task manages the structure and examination of mounting structure in sunlightbased force plants and different sun powered items. India has a plenitude of daylight and the pattern of consumption of petroleum products is convincing vitality organizers to the achievability of utilizing inexhaustible wellsprings of vitality like sun-based wind, and so forth. Under different government plans and activities, to support the usage of sustainable tasks. in the future, there will be a tremendous interest in the force and henceforth sun-powered is a spotless and rich vitality. Along these lines, the sunlightbased items must be planned in an idealistic manner to decrease the expense and improve the presentation. The force age system will centre usage of non-regular vitality sources to its fullest accessibility while focusing on ideal limit use of existing plants, innovation up a degree for ease age, controlling information costs, enhancement of fuel blend for long haul accessibility of fuel for new augmentations mounting structures are the base for the sun-powered board and go about as a seat. The mounting structure goes about as a significant job in the exhibition of the sunoriented force plant. the plan examination includes a short report about sunlight-based force plants and the job of mounting structure in it. In the presentation of the sunlight-based force plant mounting structure assumes an imperative job. Thus, the pressure strain investigation and warm practices of the mounting structure are breaking down with two unique materials like Stainless steel and Aluminium. The presentation of the mounting structure made up of this material is investigated, created, and tried. As temperature dispersion and stress-strain relationship regarding the material utilized are
\end{abstract}

investigated as they assume an indispensable job in the presentation factor thus a streamlined structure is proposed.

Keywords: Mounting structure, tracker

\section{INTRODUCTION}

A sun-powered tracker is a gadget that arranges a payload toward the Sun. Payloads are generally sun powered boards, explanatory troughs, Fresnel reflectors, focal points, or the reflections of a heliostat. For level board photovoltaic frameworks, trackers are utilized to limit the edge of frequency between the approaching daylight and a photovoltaic board, now and again known as the cosine mistake. Decreasing this edge builds the measure of vitality created from a fixed measure of introduced powerproducing limit.

Mounting structures are the base for the sunlightbased board and go about as a seat. The mounting structure acts as a significant job in the presentation of the sun-powered force plant. The plan examination includes a concise report about sun powered force plants and the job of the mounting structure in it. In the presentation of the sun, the oriented force plant mounting structure assumes an essential job. Consequently, the pressure strain investigation and the warm practices of mounting structures broke down with two unique materials like aluminium and tempered steel. The presentation of the mounting structure made up of this material is examined, manufactured, and tried.

The GPS beacon in our model. It is the one that follows the sun's development for the day and gives continuous reflection to the sun-oriented board. The 
sunbeams will fall on the sun-oriented board in two different ways, which is, they will fall legitimately on the sunlight-based board and the reflector will mirror the occurrence beams on the sun-powered board. Assume at the hour of sunrise the sun is in extraordinary east the reflector will adjust itself in some situation by which the occurrence beams will fall on the sun-powered board. Presently when the earth turns and the sun gets moved from its previous position the impression of the episode beams will likewise change. In this way, subsequently, the light will fall on the sensors kept on each side of the sunlight-based board. The following circuit is intended to the point that when reflection falls on the state the sensor appended to one side of the board, the tracker will move towards the left, and the other way around. Comparative is the situation when the reflection falls on the sensor joined at the highest point of the board; the circuit will make the tracker move downwards. We here have attempted to unite two straightforward standards. One being, the typical rule of frequency and reflection on which our tracker works. Also, the other is the rule on which the sun-oriented board works, which is on the occurrence of the sun-powered beams. The photovoltaic cells will create power. These two standards are consolidated there and because of which we can get almost twofold the yield which the board gives typically. Unequivocally the tracker is obligated for two sorts of turns, on will be on the vertical hub and other is on the even hub. The prior is or on the other hand, the right-left development of the reflection, and the last is for the up-down development of the reflector, for adjusting reflection on the board.

\section{MATERIALS: INVESTIGATIONS AND EXAMINATION}

The materials which are to be examined and thought about is Aluminium and Stainless-Steel. The investigations materials both have high consumption obstruction in the environment. Fundamentally both the materials have high return quality and wear quality. The accompanying examinations and correlation dependent on the materials properties, cost, and accessibility. Aluminium has a higher oxidation and consumption opposition than hardened steel. Aluminium is incredibly lightweight, while hardened steel is overwhelming. Alongside being lightweight, it is solid, making it an extraordinary material to use for basic segments and gear in the kitchen. Aluminium is likewise an incredible conductor of warmth, which makes it the ideal material where great warmth conductivity is required. From a value point, aluminium is additionally less expensive than treated steel. The defeat of aluminium is that it is a lot harder to shape and will regularly break under the press, making it a troublesome item to use for ledges.

In the finishes, every material has its upsides and downsides and them two are extremely mainstream in metal cladding creation for protection. Treated steel is more grounded, while aluminium is lighter. Aluminium conducts heat far superior to treated steel, while hardened steel is less responsive to food. Aluminium is less expensive and simpler to clean, however pure can be framed into shapes. Quality

Aluminium has an elasticity of $276 \mathrm{MPa}$ and a thickness of $2.81 \mathrm{gcm}-3$. Aluminium is, consequently, lighter than steel. Treated steel has an elasticity of $505 \mathrm{MPa}$ and a thickness of $8 \mathrm{~cm}-3$. Hardened steel is, in this manner, more grounded than aluminium.

\section{Consumption Resistance}

While pliability is significant for assembling, aluminium's most noteworthy trait is that it is consumption safe with no further treatment after it is spun. Aluminium doesn't rust. With aluminium, there is no paint or covering to wear or scratch off. Steel or "carbon steel" in the metal's reality (rather than tempered steel) generally should be painted or rewarded in the wake of turning to shield it from rust and erosion, particularly if the steel part will be grinding away in a clammy, sodden or grating condition.

\section{Cost}

Aluminium is more costly than hardened steel when you analyse it by weight. In any case, aluminium is around $1 /$ third the heaviness of tempered steel, and when you analyse the expense of a similar volume of material, treated steel is considerably more costly, for the most part by about $30 \%$

\section{Pliability}

Aluminium is a truly attractive metal since it is more mouldable and versatile than steel. Aluminium can end up in a good place and make shapes that steel can't, regularly framing further or increasingly complex turning. Particularly for leaves behind profound and straight dividers, aluminium is the material of decision. Steel is an exceptionally intense and versatile metal yet can't for the most part be pushed to indistinguishable outrageous dimensional cut off points from aluminium without breaking or tearing during the turning procedure. 


\section{International Journal of Engineering Applied Sciences and Technology, 2020 Vol. 5, Issue 4, ISSN No. 2455-2143, Pages 233-236 \\ Published Online August 2020 in IJEAST (http://www.ijeast.com)}

\section{WEIGHT}

Indeed, even with the chance of erosion, steel is more diligently than aluminium. Most spinnable tempers and combinations of an aluminium gouge, ding, or scratch all the more effective when contrasted with steel. Steel is solid and less inclined to twist, twist or curve underweight, power or warmth. In any case, the quality of steel's exchange off is that steel is a lot heavier/a lot denser than aluminium. Steel is normally 2.5 occasions denser than aluminium. The last utilization of the part will at last figure out which material the part would be spun from, adjusting all the impediments and preferences of every material. On some turning, it's a simple call, while others are a harder decision. The passivation process cleans the outside of the metal of contaminations and advances the arrangement of the typical defensive oxide layer. The erosion of the mounting structure occurs by contact with climate conditions. Aluminium is more destructive safe than tempered steel. As a rule, aluminium is preferable to metal to use over tempered steel where there is worry about consumption due to top contact with mounting structure. What's more, thus we can realize that the aluminium is generally best in assembling the mounting structure.

\section{RESULT}

The sun-based board supporting structure is examined for a given material and determined for a given point. the outcome is as per the following.

\section{Aluminium:}

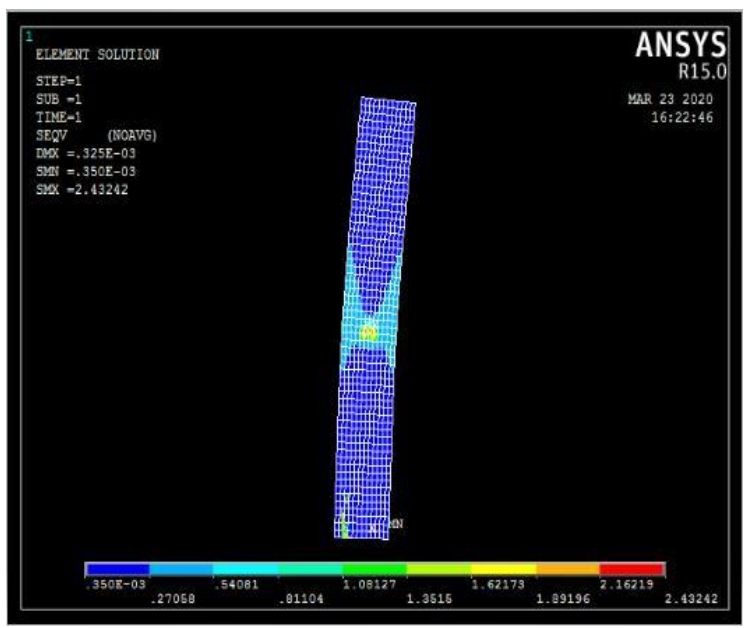

At $90^{\circ}$ : The above figure shows the high wind pressure follow up on the aluminium mounting structure part. At 90 degree the part gets high wind power at the yellow locale and lower wind force at the dark blue region

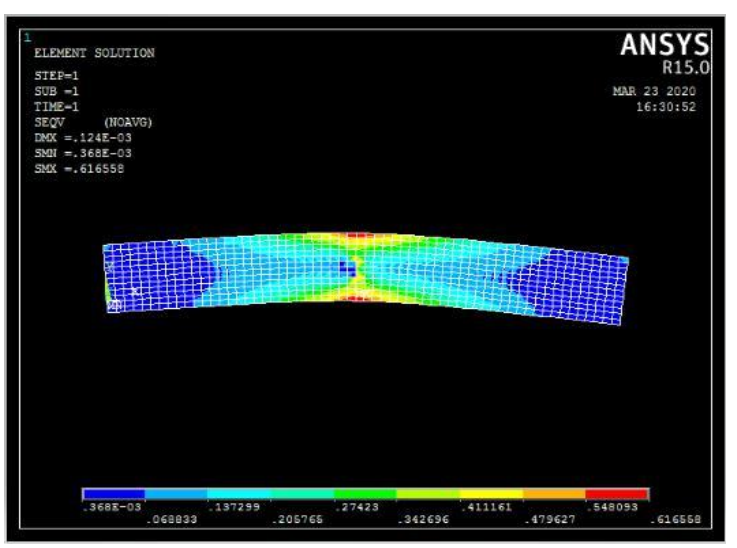

At $180^{\circ}$ : The above figure shows the high wind stress act on the aluminium mounting structure part. At 180 degrees the part gets high wind force at the yellow region and lower wind force at the dark blue region.

\section{STAINLESS-STEEL:}

The solar panel supporting structure is made by stainless-steel is analysed forgiven and calculated by a given angle of rotation. the result is as follows.

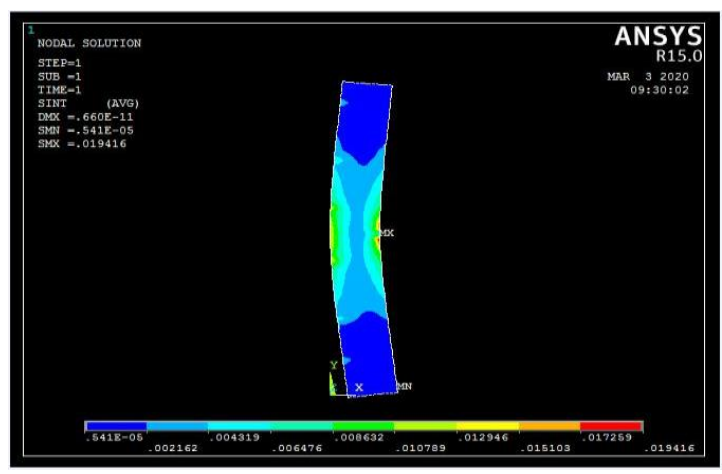

At $90^{\circ}$ of rotation: The above figure shows the high wind stress act on the stainless-steel mounting structure part. At 90 degrees the part gets high wind force at the yellow region and lower wind force at the dark blue region.

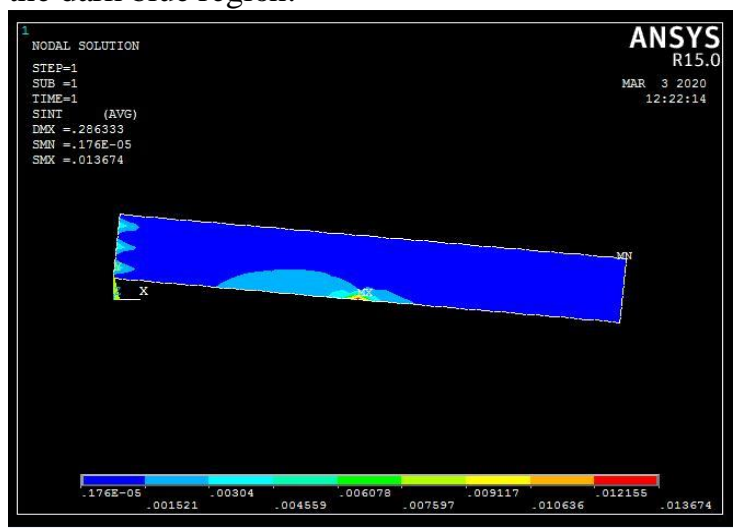




\section{International Journal of Engineering Applied Sciences and Technology, 2020 \\ Vol. 5, Issue 4, ISSN No. 2455-2143, Pages 233-236 \\ Published Online August 2020 in IJEAST (http://www.ijeast.com)}

At $180^{\circ}$ : The above figure shows the high wind stress act on the stainless-steel mounting structure part. At 180 degrees the part gets high wind force at the red region and lower wind force at the dark blue region.

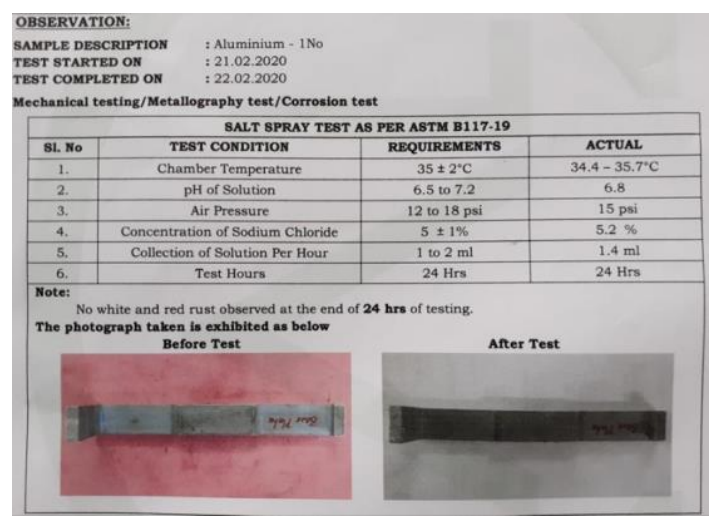

Consumption test result

\section{CONCLUSION}

The sun-based board bolster structure is planned and tried utilizing PC based limited component programming ANSYS. The mounting structure material aluminium is tried practically by the salt shower technique to know its consumption opposition property. Tempered steel likewise tried, similarly, to test its consumption safe property to make a mounting structure. Both the trial of the material is contrasted and with pick the better one, for this the underneath conversation is finished.

Different properties of both the materials like quality, weight, warm conductivity, explicit warmth limit, electrical conductivity, pliability, and so forth., Moreover, the primary concern is considered to pick the material for example cost of the material. The mounting structure to made for the sun-oriented board is made by the material should be less assembling cost, producing strategy, and less time utilization. The above conversation is done the choice is taken to which material is better for creation of sun powered board mounting structure. Aluminium is the favoured material than tempered steel to make programmed sunlight based following framework mounting structure.

\section{REFERENCE}

[1]International Energy Agency. (2009) [Online]. Available:

http://www.iea.org/Textbase/nppdf/free/2009/key _stats_2009.pdf

[2] Ed. Mary D. et al.,, Series on Photoconversion of Solar Energy, V. 1, Imperial College Press, UK.

[3]M.A. Panait and T Tudorache,(2008) "A Simple Neural Network Solar Tracker for Optimizing Conversion Efficiency in Off-Grid Solar Generator" Intl. Conf. on Renewable Energy and Power quality, no. 278.

[4]Piao, Z.G. Park, et al.,(2005) " A study on the tracking photovoltaic system by program type," Intl. Conf. on Electrical Machines and Systems, vol. 2, pp. 971-973

[5]C. Hua and C. Shen,(2012) "Comparative study of peak power tracking techniques for solar storage system,' Applied Power Electronics

[6]A. K. Saxena and V. Dutta,(1990) "A versatile microprocessor based controller for solar tracking," Photovoltaic Specialists Conference,

vol. 2, pp. 1105-1109.

[7]B. Koyuncu and K. Balasubramanian,(1991) "A microprocessor controlled automatic sun tracker," IEEE Transactions on Consumer Electronics, vol. 37, no. 4, pp. 913-917

[8]O. Bingol, A. Altinta, and Y. Oner, "Microcontroller based solar- tracking system and its implementation," Journal of Engineering .

[9] Robert A. Sielski. (2007) Research Needs in Aluminum Structure.Naval ArchitectStructures,Indio, California,

[10] Taylor, D.A. (1980) Merchant ship construction. Butterworth \&Co.(Publishers) Ltd. Pages 25-28. USA.

[11] Soedarsono et al., (2012a) Advanced Materials Research, 415-417 (2012), p. 831

[12] L. Yang et al.,Scripta Mater, 69 (2013), p. 242 